\title{
A “JUSTIÇA TERAPÊUTICA" E O CONTEÚDO IDEOLÓGICO DA CRIMINALIZAÇÃO DO USO DE DROGAS NO BRASIL
}

\author{
Pedro Luciano Evangelista Ferreira \\ Advogado, mestre em Criminologia e Direito Penal pela UCAM-RJ e professor da Escola da \\ Magistratura do Paraná - Núcleo Ponta Grossa, das Faculdades Integradas Curitiba-PR e \\ do Centro Universitário Positivo-PR. \\ e-mail: pedroluciano@brturbo.com.br
}

RESUMO: O processo de criminalização do uso de drogas ilícitas no Brasil começou já no período colonial. Desde então, várias medidas têm sido aplicadas na tentativa de conter o consumo, restando infrutíferas sob o aspecto da contenção do consumo, mas eficazes sob o aspecto da criminalização de classes sociais economicamente desfavorecidas e/ou estigmatizadas. Inicialmente seguiu-se a orientação patológicoclínica para depois se adotar a postura bélica. A proposta da "justiça terapêutica" hoje é adotada em alguns estados brasileiros como uma "nova" solução, mas como o histórico da política criminal brasileira revela, tal proposta não passa da reformulação cíclica de uma antiga postura que reforça o binômio "doença-crime" e atende aos interesses das classes hegemônicas como eficaz instrumento de controle social.

PALAVRAS-CHAVE: Direito Penal. Criminalização do uso drogas. Justiça terapêutica. Controle social. 


\section{CONSIDERAÇÕES INICIAIS}

O presente estudo tem por objetivo pontear alguns aspectos da "justiça terapêutica", as relações existentes entre o Direito, o uso de drogas (lícitas e ilícitas) e a sociedade, com especial destaque para a sociedade e a realidade brasileiras.

Em observância à limitação do espaço gentilmente concedido, desde já insta esclarecer que não há a pretensão de trabalhar com todas as inúmeras questões que as drogas suscitam sob os prismas médico, ético, jurídico e social, de modo que é necessária a realização de um corte metodológico para restringir o objeto de análise, a "atuação dos órgãos oficiais" (legislador, judiciário, policial e sanitário), tanto no processo de criação das leis quanto no método de aplicação e cumprimento das mesmas, analisando mais especificamente a proposta da denominada "justiça terapêutica" e algumas características da política criminal de drogas em nosso país, como resultado da interação existente entre a sociedade brasileira e os usuários de drogas tanto lícitas como ilícitas.

Destaca-se ainda, o surgimento de certas inverdades e mitos contidos no discurso oficial que possuem o papel de legitimar e reproduzir uma estrutura políticosocial altamente seletiva e discriminatória que, não raras vezes, adota parâmetros fundados em valores econômicos em detrimento de valiosos preceitos éticos e morais, manipulando e ludibriando significativa parcela da sociedade, seja pelos meios de comunicação (mass media) ou pela atuação das "instâncias de controle" em relação a certos comportamentos e indivíduos de classes sociais bem definidas.

Neste sentido, vale destacar os padrões de pensamento e as formas como são tratadas as questões envolvendo criminalidade e sistema penal quais sejam: a) PARADIGMA DA REAÇÃO SOCIAL, DA ROTULAÇÃO OU PARADIGMA INTERACIONISTA, que estuda a interação entre o sistema penal e certos indivíduos (surgido na década de 60, com o "labeling approach"), bem como seu antecessor; b) PARADIGMA ETIOLÓGICO-EXPLICATIVO OU CAUSAL-EXPLICATIVO, que busca explicações para a criminalidade e suas causas (cunhado inicialmente pela Criminologia Positiva em 1875 e adotado por várias outras correntes doutrinárias até os dias atuais).

Sobreleva notar-se, a partir desses paradigmas epistemológicos, que em uma sociedade estratificada de classes existirão duas posturas principais para 0 
trato das questões envolvendo o Sistema Penal. Posturas que poderiam ser previamente definidas como:

a) Discurso repressivo e mistificador: aplaudido pelos movimentos de "lei e ordem", pugna pelo reforço do "direito à segurança" de certas classes sociais sendo responsável pelo reforço e manutenção das relações de discriminação, dominação, neutralização e exclusão social em prejuízo das classes economicamente mais débeis e/ou vulneráveis;

b) Discurso libertário e conscientizador: perfilhado pelos vários movimentos sociais que buscam o emancipatório reconhecimento da Cidadania e a "segurança dos Direitos Humanos", livre de quaisquer preconceitos que os possam limitar, dando azo ao surgimento e ao fortalecimento de laços de solidariedade entre as classes sociais e a cooperação e participação de todos os segmentos da sociedade em um projeto de inclusão de grupos sociais mais vulneráveis e/ou que possam ser alvo de qualquer tipo de discriminação, com reconhecimento e respeito ao "outro" como expressão da própria individualidade e diversidade da vida humana, em benefício de toda a sociedade.

Para contrapor e visualizar estes discursos com maior clareza, urge realizar breve referência ao processo histórico evolutivo da legislação brasileira pertinente as drogas ilícitas. Pois é preciso estudar o passado para melhor entender o presente e vislumbrar o futuro. Passo seguinte tratar-se-á da "justiça terapêutica" que está sendo implementada em vários estados brasileiros como uma resposta da sociedade em relação ao consumo de drogas (lícitas e ilícitas) e suas conseqüências. 


\section{A POLÍTICA CRIMINAL DE DROGAS NO BRASIL (COLÔNIA, IMPÉRIO E REPÚBLICA). ${ }^{1}$}

Espera-se que o conciso estudo da política criminal de drogas no Brasil manifestada em dois principais modos de tratamento: o modelo sanitário e o modelo bélico - seja capaz de provocar maiores reflexões ao leitor consciente, no que tange a "justiça terapêutica" como uma "nova" proposta à problemática das drogas lícitas e ilícitas.

No período em que o Brasil ainda era uma colônia portuguesa, não existia uma legislação genuinamente brasileira, uma vez que todos os textos legais produzidos pela Metrópole eram aplicados nas colônias de modo que a primeira expressão relacionada ao uso de drogas está contida nas Ordenações Filipinas, mais especificamente no Livro V, LXXXIX, que utiliza o vago e impreciso termo "substâncias venenosas", expressão que perdurou por muito tempo sendo, inclusive, utilizada no art. 159 do Código Penal Brasileiro de 1890.

Após pressões internacionais - que até hoje perduram -, tem início no Brasil um processo de crescente criminalização e, por força do protocolo suplementar de assinaturas da Conferência Internacional do Ópio realizada em Haia em 1912, recepcionado em nosso ordenamento jurídico pelo Decreto n. $\stackrel{0}{2.861}$ de 8 de julho de 1914 e regulamentado pelo Decreto $\mathrm{n} .011 .481$ de 10 de fevereiro de 1915, temse implementado O MODELO SANITÁRIO que vai perdurar em nosso país por meio século. Anos depois, o Decreto Legislativo n. .4 .294 de 6 de julho de 1921 revoga o art. 159 do CP de 1890 e cria a expressão "substância venenosa que tiver qualidade entorpecente, como o ópio e seus derivados, a cocaína e seus derivados" (art. 1ํ, parágrafo único). É nesse momento que a expressão "entorpecente" começa sua longa carreira no direito brasileiro.

Segue-se uma sucessão de decretos influenciados por várias convenções internacionais - especialmente as de Genebra 1925, 1931, 1936 - realizadas com o intuito de fomentar a internacionalização do controle (de drogas). Surgem também várias listas de substâncias proibidas e nesse período o tráfico se alimenta pelo desvio das drogas de seu fluxo autorizado. Mas o que contribui para que este

\footnotetext{
1 Nota do Autor: Para um estudo histórico mais completo, recomenda-se a leitura do apurado artigo: BATISTA, Nilo. Política criminal com derramamento de sangue. In: Revista Brasileira de Ciências Criminais, n.ำ 20, São Paulo: Ed. Revista dos Tribunais, 1997.
} 
período receba a denominação de "modelo sanitário" não é apenas a forte influência positivista expressa na legislação que visualiza o usuário de drogas como um doente, mas também há que se destacar um esforço de colaboração entre autoridades judiciárias, policiais e sanitárias para o compartilhamento de saberes higienistas.

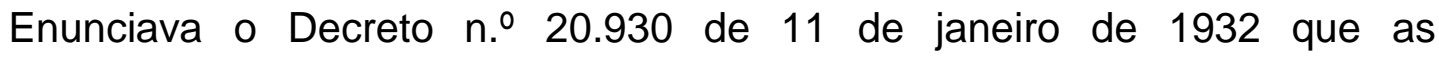
substâncias entorpecentes em geral deveriam estar elencadas em uma lista que deveria ser periodicamente revista segundo a evolução química-terapêutica (art. 1ํㅡ, par. ún.). Já a comercialização e o fabrico destas substâncias dependia de licença especial (art. $2^{\circ}$ ), o consumo dependia de receita médica que deveria ser anotada em livro próprio (art. $3^{\circ}, \S 3^{\circ}$ ) e ficaria "permanentemente a disposição das autoridades sanitária, policial e judiciária" (art. $3^{\circ}$ ). Todas as pessoas desprovidas de receitas médicas para a obtenção de substâncias controladas passaram a ser consideradas contrabandistas (art. 19). Quanto ao usuário, determina o art. 44 que a drogadição é doença de notificação compulsória e esclarece o art. 45 de referido decreto que o toxicômano ou intoxicado habitual precisava de tratamento, estando sujeitos a internação facultativa ou obrigatória, por tempo determinado ou não.

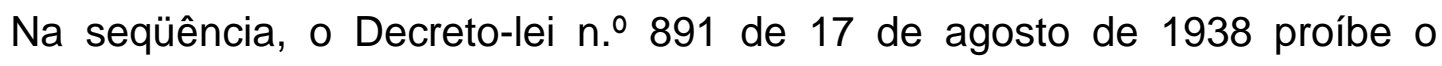
tratamento de toxicômanos em domicílio (art. 28) e o Decreto n. ำ 20.930/32 vai ainda mais longe, criando uma verdadeira aberração consubstanciada em uma delação com repercussão patrimonial para parentes até $04^{\circ}$ grau colateral como um instrumento de controle intrafamiliar. Fundado em laudo médico, o juiz poderia determinar um $3^{\circ}$ (desinteressado, obviamente) a acautelar-se dos bens e interesses do internado, que deveria ser enviado a uma "Colônia de Alienados". Pode-se imaginar quantas artimanhas foram engendradas neste período? $O$ delator ganancioso e sem escrúpulos recebia como prêmio os bens do internado e a tranqüilidade em saber que o regresso e a recuperação deste era realmente muito improvável.

Note-se que neste período o usuário de drogas não é criminalizado, tanto aquele que é dependente como o usuário eventual eram considerados doentes e deveriam ser "tratados e curados", mas não punidos. Porém, como visto acima, a forma como o tratamento era realizado constituía um "castigo" pior que a 
condenação penal, isso se lembrarmos que não pode existir pena por tempo indeterminado.

Com o citado Decreto no $20.930 / 32$ é oportuno frisar que a intervenção penal passou a ser mais rigorosa e abrangente, pois, ao contrário do Decreto ํo 4.294/21 que se restringia a punir as ações de "vender, expor a venda ou ministrar as substâncias venenosas de qualidade entorpecente" sem criminalizar a posse ilícita, com o Decreto no 20.930/32 há uma multiplicação de verbos no tipo básico, que agora passa a punir aquele que "vender, ministrar, dar, trocar, ceder ou, de qualquer modo, proporcionar" (art. 25), isso sem falar na suspensão temporária do exercício profissional quando os envolvidos fossem médicos, cirurgiões-dentistas, farmacêuticos ou qualquer outro profissional relacionado com o crime. Agora também ocorre a criminalização da posse ilícita (art. 26), da prestação do local (art. 28) que antecipam o art. 281 do CP de 1940. O controle médico-farmacêutico era rigoroso e toda a violação aos regulamentos sanitários era punível. O tráfico e a importação irregular eram inafiançáveis (art. 33).

$\mathrm{Na}$ Consolidação das Leis Penais que antecedeu o CP de 1940, o usuário estava sujeito a prévia e imediata internação pela autoridade policial em, destaquese, "hospital especial para psicopatas" para a aplicação de um tratamento de toxiprivação progressiva que deveria ser acompanhado por autoridades policiais e judiciárias. Ocorre que, se a internação em um estabelecimento médico era simples e rápida, já a sua liberação era precedida de um complexo processo de laudos médicos e decisões judiciais que muito lembravam os "alvarás de soltura", isso sem falar nas medidas policiais de vigilância do pretenso "curado" configurando o Sistema da "assistência coactiva".

É igualmente válido salientar que o rigor penal ultrapassa a tipificação de várias condutas relacionadas direta e indiretamente com as drogas ilícitas, existindo também efeitos extremamente severos (penais e extrapenais, genéricos e específicos) sobre a vida do condenado como:

- Perda do cargo se funcionário público;

- Exclusão e trancamento da matrícula se aluno de qualquer grau, tanto em estabelecimento público ou particular; 
- Proibição da concessão do sursis e do livramento condicional;

- Equiparação do crime tentado ao crime consumado;

- Expulsão do estrangeiro do território nacional;

- Reincidência era causa de duplicação da pena aplicada;

Não se pode deixar de mencionar a circunstância agravante prevista no art. 36, que é no mínimo curiosa e revela seu conteúdo moralista uma vez que "a procura da satisfação de prazeres sexuais nos crimes deste decreto, constituirá circunstância agravante". Seguiram-se outros decretos (Decreto n. 24.505/34 e Decreto n.. 891/38), ecos das intervenções internacionais para controle e repressão ao tráfico de drogas, mas que não produziram muitos efeitos porque tiveram uma vida curta, tendo em vista a proximidade com o Código Penal de 1940, atualmente em vigor. Contudo, urge salientar que com estes instrumentos legislativos houve a criminalização do consumo, a eliminação da expulsão automática para os estudantes e a formalização do compromisso médico-legal que bem caracteriza este modelo: "as autoridades sanitárias e policiais prestarão auxílio recíproco nas diligências que se tornarem necessárias ao bom cumprimento desta lei" (art. 63 do Decreto $n . .981 / 38$ ).

Com o advento do CP 1940, a resposta legal às drogas é mais ponderada, sendo que as principais modificações na matéria dizem respeito: a descriminalização do consumo, a leve diminuição dos verbos acumulados nos tipos penais e a fusão do tráfico e da posse ilícita no mesmo artigo (art. 281). No período que se segue, a atenção sobre a questão das drogas passa a ser secundária, assim permanecendo até os anos sessenta, tendo em vista um período de redemocratização por que passava o nosso país ao encerrar a "Era Vargas".

Dignos de nota, porém, são alguns decretos como o Decreto-lei n. ${ }^{-} 4.720$ de 21 de setembro de 1942, que taxava as normas gerais para o cultivo de plantas entorpecentes e para a extração, transformação e purificação de seus princípios ativo-terapêuticos; o Decreto-lei n. 8.646 de 11 de janeiro de 1946 que alterou o Decreto-lei n.o 891 de 25 de novembro de 1938 e centralizava em determinada repartição pública o poder de autorizar a importação e exportação de entorpecentes

\footnotetext{
2 BATISTA, Nilo. op. cit. p. 83.
} 
para "drogarias, laboratórios, farmácias e estabelecimentos fabris"; e o Decreto-lei n. .20 .397 de 14 de janeiro de 1946 que regulamentava a indústria farmacêutica no país, mais especificamente nos arts. 19 usque 26 que tratavam dos laboratórios que fabricassem especialidade com qualidades entorpecentes.

Destaca Nilo Batista - com a argúcia que lhe é peculiar - que neste período as indústrias brasileiras começam a crescer e sua atenção aumenta sobre o lucrativo mercado de drogas (agora lícitas porque regulamentadas em lei) uma vez que "...a conversão da droga em mercadoria de um lado sinalizava os bons negócios futuros no âmbito silencioso das fármaco-dependências". ${ }^{3}$ É o uso de drogas lícitas para o "tratamento" do uso de drogas ilícitas. Enfim, são drogas e drogas.

Com o golpe militar, a postura dos órgãos oficiais com relação às drogas paulatinamente toma outro rumo e agora - mais uma vez por força de pressões externas - uma nova forma de tratamento surge vigorosa: o Modelo Bélico. Isso não significa que os estereótipos criados pelo modelo sanitário tenham sido completamente abandonados, porém, o que caracteriza este novo modelo é a utilização de verdadeiros "métodos de guerra".

O contexto histórico é bem representativo e favorece a mudança do modelo sanitário para o modelo bélico. Vale lembrar que esta é a época da "guerra fria", da bipartição do mundo entre o capitalismo (EUA e Otan) e o socialismo (URSS e Pacto de Varsóvia), da corrida armamentista e da militarização das relações internacionais, isso sem falar nos movimentos de contracultura, a exemplo dos "hippies".

No Brasil, regido pela ditadura militar, impera a doutrina da Segurança Nacional com o Al-5, a censura, DOI-CODI, DOPS e os seus porões. Com o Decreto-lei n.․ 385 de 26 de dezembro de 1968 há a equiparação do usuário "que traz consigo substância entorpecente" ao traficante, provocando a reação de poucos juristas tendo em vista o autoritarismo reinante. No entanto, os tribunais tentaram amenizar esta situação com uma aplicação mais equilibrada do dispositivo legal, estando cientes de que uma sentença iníqua, embasada nesta absurda equiparação, poderia estar legalmente certa, porém, representava um verdadeiro desastre sob o aspecto social. A conseqüência é que ao invés de muitas condenações equilibradas, houve sim muitas absolvições para proteger o réu

\footnotetext{
${ }^{3}$ BATISTA, Nilo. op. cit. p. 84.
} 
primário e os portadores de pequena quantidade de substância entorpecente, como bem anota Menna Barreto. ${ }^{4}$

Na seqüência, a Lei n. 5.726 de 29 de outubro de 1971 estabelece em seu art. $1^{\circ}$ ser "dever de toda a pessoa física ou jurídica colaborar no combate ao tráfico e uso de substâncias entorpecentes" (negritou-se) e agora qualquer opinião que contrariasse a repressiva política de drogas configuraria um crime omissivo.

Sob pena da perda do cargo, os diretores de escolas tinham a obrigação de informar às autoridades qualquer suspeita de alunos envolvidos com o tráfico ou uso de drogas (art. 7ํㅡ. par. ún.) o que poderia ocasionar o trancamento da matrícula como previa o art. 8ํ. No caso de estrangeiros, os crimes de uso e tráfico de drogas eram equiparados aos crimes contra a segurança nacional, sendo alteradas algumas regras para a expulsão, bem com a previsão de uma investigação rápida de apenas 05 (cinco) dias (art. 22). As penas foram aumentadas de "6 meses a 2 anos" para "1 a 5 anos" e foi acrescentado mais um verbo (oferecer), isso sem falar em mais uma aberração jurídica: a "quadrilha de dois" (!!!).

Agora as autoridades militares e policiais vislumbravam o usuário e 0 traficante de drogas como o novo "inimigo interno", já a disseminação do uso de drogas junto aos jovens era tratada como tática comunista para a conquista do mundo ocidental pela desestruturação de valores cristãos e instituições como a família e a igreja e, portanto, somente estratégias e autoridades militares seriam capazes de arrostar adequadamente a questão. Pensamentos mais extremados chegaram a pugnar pela inclusão do crime de tráfico dentre os crimes de lesa-pátria e seu enquadramento na temível Lei de Segurança Nacional.

É a época da "caçada as bruxas", da cruzada bélica, moral e religiosa que permitia uma guerra sem restrições e legitimava as mais abusivas ações das autoridades policiais, isso sem falar nas "investigações movidas a tortura e sangue" realizadas no submundo dos porões e calabouços, nos desaparecimentos e execuções sumárias e no grande aumento da população carcerária.

Passo seguinte temos a Lei n. 6.368 de 21 de outubro de 1976 (que recebe a alcunha de "Lei antitóxicos") sendo regulamentada pelo Decreto n. 78.992 de 21

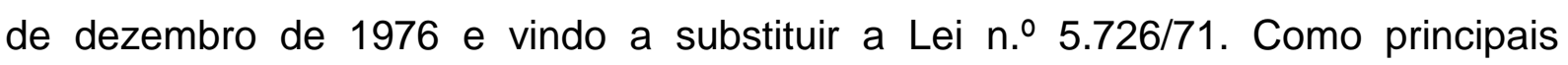

4 MENNA BARRETO, João de Deus Lacerda. Estudo geral da nova lei de tóxicos. 3a ed. rev. e aumentada. Rio de Janeiro: Freitas Bastos, 1982. p. 30. 
inovações, temos a substituição da locução "combate" pela locução "prevenção e repressão" para fundamentar aquele dever jurídico entabulado no art. 1․․ Houve também a substituição do termo "viciado" por um mais adequado, que é o de "dependente". Alunos surpreendidos com drogas não têm a sua matrícula necessariamente trancada e os diretores não são mais obrigados a serem delatores, embora sua inércia ante o conhecimento de certo envolvimento de alunos com drogas possa responsabiliza-los penal e administrativamente. Os dependentes, cujo quadro clínico ou a natureza de suas manifestações psicopatológicas o exigirem, serão submetidos a tratamento sob regime de internação hospitalar (art. 10), é o "direito de tratar" que compete a União", porém, como exposto, a internação compulsória de toxicômanos não é novidade em nosso ordenamento jurídico.

A multiplicação e acumulação de verbos ocorrida em todo o processo de criminalização de certas "substâncias entorpecentes" chegou a seu ápice (isso se as leis futuras não elencarem mais alguns "verbinhos") tanto que o art. 12 atualmente agrega o significativo número de 18 (!!!) verbos: "Art. 12. Importar ou exportar, remeter, preparar, produzir, fabricar, adquirir, vender, expor à venda ou oferecer, fornecer ainda que gratuitamente, ter em depósito, transportar, trazer consigo, guardar, prescrever, ministrar ou entregar, de qualquer forma, a consumo substância entorpecente ou que determine dependência física ou psíquica, sem autorização ou em desacordo com determinação legal ou regulamentar."

Isso sem falar em mais alguns verbos relacionados nos incisos $1^{\circ}$ e $2^{\circ}$ do mesmo artigo, que prevêem mais algumas modalidades delituosas, porém, temos agora mais um aumento na duração das penas que, para o art. 12 (tráfico), é de 3 a 15 anos de reclusão e multa. Também houve disciplinamento do processo legal e, conforme estabelece o art. 35, o réu condenado por tráfico deve recolher-se à prisão para poder apelar.

Com o advento da Constituição Federal de 1988 foram revogados alguns

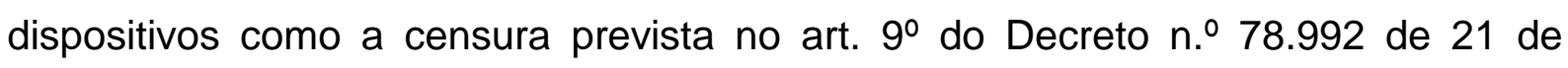
dezembro de 1976, contudo, agora o tráfico de drogas é crime inafiançável e insuscetível de anistia e graça, conforme estabelece o art. 5º, inciso XLIII.

5 SANTOS, José Wilson Seixas. Lei antitóxicos comentada. $2^{\underline{a}}$ ed. rev. atual. Leme: Livraria de Direito, 1994. P. 56. (destacou-se) 
Na seqüência temos a famigerada Lei n.. 8.072 de 25 de julho de 1990, mais conhecida como "Lei dos Crimes Hediondos" - por muitos considerada uma "lei hedionda" por certas impropriedades jurídicas cuja apreciação escapa os contornos do presente trabalho - que também proíbe o indulto e a liberdade provisória para o tráfico de drogas, além de duplicar os prazos judiciais, garantindo assim uma prisão provisória mais longa para os acusados pelos crimes dos arts. 12, 13 e 14 da Lei n.. 6.863/76.

Por fim, impende notar que o contexto histórico destas últimas leis é totalmente diverso, devido ao fim da "guerra fria" e à abertura política brasileira, porém o rigor penal ainda é presente, não mais contra os comunistas ou subversivos, mas contra os marginais e traficantes, para o novo estereótipo do inimigo que compromete a segurança nacional (das classes hegemônicas e mais abastadas) surge a figura do jovem latino-americano, do imigrante pobre, do jovem negro das favelas, do traficante de drogas ilícitas, daqueles que não se encaixam no sistema capitalista monopólico de base industrial, como mencionado nos tópicos anteriores, revelando enfim a "...funcionalidade mítica da droga para o exercício daquele controle social penal máximo sobre as classes marginalizadas, cujos filhos são recrutados para trabalhar nos arriscados estágios de produção e comercialização...".

O estágio mais recente do processo histórico-evolutivo da legislação brasileira está consubstanciado na Lei ํㅜ 10.409/02, que entrou em vigor no dia 27 de fevereiro de 2002 e dispõe sobre a prevenção, o tratamento, a fiscalização, o controle e a repressão à produção, ao uso e ao tráfico ilícitos de produtos, substâncias ou drogas ilícitas que causem dependência física ou psíquica, assim elencados pelo Ministério da Saúde, e dá outras providências.

Ocorre que, quando da sanção presidencial, inúmeros foram os dispositivos vetados (cerca de $30 \%$ de todos os dispositivos aprovados pelo Congresso), inclusive $O$ art. 59 que revogava a Lei $n^{\circ} 6.368 / 76$. O projeto que seguiu para a presidência, e que já apresentava problemas de sistematização, devido aos inúmeros substitutivos aprovados durante a sua longa tramitação, ficou ainda mais confuso após os vetos.

\footnotetext{
${ }^{6}$ BATISTA, Nilo. op. cit. p. 89.
} 
As principais inovações são de caráter procedimental - como a defesa preliminar - vez que o capítulo que instituía novos delitos (capítulo III) foi vetado, em sua totalidade, causando sério embaraço para a eficácia dos dispositivos mencionados, sem contar os inúmeros problemas de interpretação. Dificuldades também existem em relação aos dispositivos que se referem ao tratamento do dependente e do usuário de drogas, em razão do veto ao artigo que previa o tratamento como uma das medidas aplicáveis a determinados crimes.

A referida lei deu um tratamento mais abrangente à questão das drogas,se preocupando com a fiscalização e o controle e dando ênfase a prevenção com a previsão de seis medidas: $1^{a}$ ) Celebração de convênios nacionais e internacionais (art. $4^{\circ}$ ); $2^{a}$ ) Orientação escolar (art. $4^{\circ}$, $\S$ único); $3^{\text {a}}$ ) Elaboração e análise de dados e informações (art. $\left.5^{\circ}\right) ; 4^{\underline{a}}$ ) Inspeções locais (art.6ํ); $5^{\text {a }}$ ) Elaboração de programas voltados à prevenção (art. 10); e $6^{\mathbf{a}}$ ) Programas de reinserção no mercado de trabalho de dependente ou usuário (art. 12, § 3º).

A nova Lei, em seu art. 11, prevê que tanto o dependente quanto o usuário de produtos, substâncias ou drogas ilícitas que causem dependência física ou psíquica, relacionados pelo Ministério da Saúde, devam ser encaminhados para tratamento. Como observam vários membros da comunidade jurídica e médica, a eficácia de um tratamento compulsório, pelo simples envolvimento do agente com substância entorpecente, sem a prévia distinção entre o usuário e o dependente, é muito questionável. "Assim como nem todos que tomam um copo de uísque são alcoólatras, também há quem use drogas sem ser dependente. Em termos médicos, é risível condená-lo a tratamento compulsório"7

O tratamento compulsório previsto como uma das medidas possíveis no projeto aprovado (art. 21, II), para o caso de condenação por crime de consumo pessoal, foi vetado pelo Presidente, juntamente com todos os demais dispositivos contidos no capítulo que o abrigava (Capítulo III). Por esta razão, o verdadeiro alcance do tratamento e da internação previstos na Seção II do Capítulo II da Lei 10.249/02 e a questão da "justiça terapêutica" devem ser observados com cautela. Quatro são as hipóteses:

\section{1ํ) Tratamento espontâneo}


$\mathrm{O} \S 5^{\circ}$ do art. 12 traz uma obrigatoriedade que deve ser atendida nos casos de internação ou de tratamento por ordem judicial. Contudo, nada impede que a internação ou o tratamento serem espontâneos.

$\left.2^{a}\right)$ Obrigatoriedade de tratamento para os casos de inimputabilidade (art. 29 da Lei 6.368/76)

A Lei 6.368/76 permanece em vigor, no que não foi contrariada pela nova Lei. Desta forma, nada obsta que permaneça sendo aplicado o artigo 29 da Lei 6.368/76, por meio do qual "quando o juiz absolver o agente, reconhecendo, por força da perícia oficial, que ele, em razão de dependência, era, ao tempo da ação ou da omissão, inteiramente incapaz de entender o caráter ilícito do fato ou de determinar-se de acordo com esse entendimento, ordenará seja o mesmo submetido a tratamento médico." A lei anterior previa o tratamento obrigatório sob o regime de internação hospitalar nas situações em que o "quadro clínico do dependente ou a natureza de suas manifestações psicopatológicas assim o exigirem" (art. 10), tratando-se "de medida meramente profilática, sem caráter penal, que tem por objetivo único promover o tratamento e a cura do vício, no caso do dependente e a eliminação dos fatores físico-psíquicos que levam o usuário ao consumo da droga."

\section{3a) Tratamento como pena substitutiva}

Com o advento da Lei 9.714/98, para as hipóteses previstas no art. 16 da Lei 6.368/76, possibilitou-se a aplicação de sanções substitutivas, visto que a pena não ultrapassa o limite de quatro anos (art. 44 do CP). Ao que tudo indica, não existe qualquer obstáculo à possibilidade do magistrado instituir o tratamento ou internação como pena substitutiva, na hipótese do uso de substância entorpecente. O problema é a ineficácia da medida, já que na área da saúde não se tem dúvida de que somente se consegue algum resultado positivo quando o tratamento é realizado com a anuência do paciente.

\footnotetext{
${ }^{7}$ Lei descuidada. Folha de São Paulo, 6 jan. 02, p. A-2.
} 


\section{$4^{\circ}$ ) Tratamento como conseqüência da transação penal}

É possível fixar o tratamento do dependente como medida alternativa nos juizados especiais (Leis 9.099/95 e 10.259/01). Porém, em se tratando de transação penal, o consenso do acusado deve estar presente, tanto no que diz respeito ao tratamento, como no que se refere a aceitação da proposta ministerial pelo agente (art. 76 da Lei 9.099/95).

\section{A PROPOSTA DA "JUSTIÇA TERAPÊUTICA"}

Atualmente observa-se o crescimento de manifestações e estudos a respeito da chamada "justiça terapêutica" que é um programa judicial dirigido aos infratores envolvidos com drogas lícitas e/ou ilícitas, que envolve medidas de saúde em substituição aplicação das penas previstas em nosso ordenamento jurídico.

Segundo a sistemática adotada, o membro do Ministério Público propõe ao infrator que ele seja avaliado por equipe de saúde, interdisciplinar e, se indicado, receba a atenção terapêutica necessária ao seu caso. A proposta ministerial é feita para o acusado em juízo, com o crivo do juiz e do seu defensor. Se aceita a proposta, a mesma é homologada pelo juízo e o processo é suspenso.

Para os defensores da "justiça terapêutica", a mesma pode ser utilizada com amparo em outros textos legislativos que não somente a atual lei de tóxicos, senão vejamos: a. No Estatuto da Criança e do Adolescente (Lei no 8.069/90), as medida protetivas do Art. 101, aplicadas como medidas sócio-educativas do Art. 112; b. Na suspensão condicional do processo, segundo os princípios do Juizado Especial Criminal; c. Na transação penal, segundo os princípios do Juizado Especial Criminal; d. Na suspensão condicional da pena - sursis do Art. 77 do Código Penal; e. No livramento condicional do Art. 85 do Código Penal; f. Na limitação de fim de semana, como pena restritiva de direitos, do Art. 43 do Código Penal.

São destacadas algumas vantagens da "justiça terapêutica", como no fato de evitar a prisão e seus efeitos nefastos, o que representa um menor custo social e financeiro para o Estado. $O$ arquivamento do processo também é extremamente benéfico por não gerar antecedentes criminais. Argumenta-se também sobre a maior integração entre os operadores do direito e os profissionais da saúde, mas como 
visto essa integração não é nenhuma novidade, marcando um possível retorno ao "modelo sanitário", já adotado anteriormente pela política criminal de drogas no Brasil.

Como desvantagens, observe-se a equiparação que muitas vezes é feita entre o usuário não dependente com o usuário dependente, já que a proposta atinge a todo e qualquer agente que tenha praticado um crime envolvido com as drogas. $O$ modelo força o usuário de drogas não dependente a fazer um tratamento de que não precisam. Já o dependente somente poderá optar pelo tratamento se, durante o processo de drogadição, o sistema penal não criminalizar sua conduta, caso contrário o tratamento será obrigatório, bem como o processo de rotulação.

Para muitos, o consumo deve ser tratado como questão de saúde pública e não com o sistema penal, que deve tratar do tráfico organizado. Neste sentido, a "justiça terapêutica” reforça o binômio droga-crime (medicalização da delinqüência), como um possível e sutil retorno ao sistema do duplo-binário que previa a aplicação de medidas de segurança pós-delitivas indeterminadas, uma vez que o tratamento e seu resultado não podem estar vinculados ao processo penal. No que diz respeito ao usuário, a resposta penal é imprópria, porque o indivíduo que necessita de tratamento e educação somente os terá - realmente - se não for selecionado pelas agências oficiais de controle.

$\mathrm{Na}$ visão de muitos, a "justiça terapêutica" seria a versão tupiniquim das "drug courts" norte-americanas, que cooperam com a criminalização ao exigir testagens de abstinência obrigatórias, comparecimento regular às terapias, etc.

A esse propósito, nota-se mais uma vez que a correlação "crime-doençapecado" tem sido bem utilizada para a questão das drogas ilícitas, de modo que uma sentença condenatória teria o efeito de "punir-curar-exorcizar" o "criminoso-doentepecador", com bem demonstra a história. Não pode ser desconsiderada também uma certa "geo-política das drogas" que se expressa na forte influência dos organismos internacionais (encabeçados por certos países), sobre o processo global de criminalização das drogas. Influência esta motivada por interesses econômicos aliados a uma polarização falaciosa dos "países-consumidores" como vítimas e dos "países-produtores" como agressores, justificando intervenções militares e medidas

\footnotetext{
${ }^{8}$ Nota do Autor: Para maior aprofundamento sobre a "geopolítica das drogas" vide o profícuo trabalho de Rosa Del Olmo: A face oculta da Droga. Tradução de T. Ottoni. Rio de Janeiro: Revan, 1990.
} 
de controle externo "para evitar o tráfico de drogas ilícitas", mesmo que isto comprometa a soberania nacional de muitos países e os direitos de muitas pessoas, especialmente as classes "suburbanas" como se fossem "sub-cidadãos" ou cidadãos de segunda classe despojados de uma significativa esfera de direitos. Verdadeiras vítimas de violações livres e "legítimas" praticadas pelas instâncias oficiais de controle em nome da verdadeira "guerra santa contra as drogas", sob aplausos da grande massa. É triste observar que o reprovável princípio cunhado por MAQUIAVEL tem sido habilmente aplicado: "Os fins justificam os meios". Ad exemplum, vale esclarecer que nas imediações dos locais da América do Sul, onde os fuzileiros navais norte-americanos despejaram suas poderosas drogas para destruir plantações de coca, começam a nascer agora crianças deformadas. ${ }^{9}$ Onde está a preocupação com a saúde pública?

É bom salientar que a intensidade das medidas repressivas é diretamente responsável pelo aumento do preço final das drogas ilícitas, proporcionando um incremento substancial do lucro obtido pelos altos escalões - não raras vezes políticos, empresários ou outros cidadãos detentores de grande respeitabilidade e status social. Também é pesaroso reconhecer que "quando as redes do Sistema Penal são lançadas, só os peixes pequenos é que são capturados".

A partir da posição escolhida pelo Estado, surge um parâmetro geral para o bem de "toda a sociedade", ainda que estejam fortemente resguardados os interesses das classes dominantes (verbi gratia, propriedade privada dos meios de produção, "mais- valia", venda da força de trabalho, lei da oferta e da procura) dos quais decorre um fator de influência na atuação do sistema penal como instrumento de reprodução ideológica destes interesses e manutenção das conseqüentes relações sociais existentes entre as classes dominantes e as classes dominadas. Há muito tem sido passada a imagem de que o ordenamento jurídico, mecanismo natural de organização social, é construído a partir do consenso para o bem de toda a sociedade, o que não passa de um grande sofisma como destaca Capeller:

Interessa aos detentores do poder reproduzir ideologicamente uma falsa imagem de que o Estado é imparcial na aplicação do sistema legal (que compreende a criminologia), sempre tentando equilibrar e conciliar os interesses dos diversos grupos sociais. Mas, apesar de que a classe dominante não está controlando diretamente o sistema legal, o sistema penal

${ }^{9}$ BATISTA, Nilo. op. cit. p. 62 
defende os interesses desta classe. Assim, 'o controle do crime se torna o maior esquema do Estado na sua promoção da sociedade capitalista' ${ }^{10}$

As características do discurso penal e suas funções desempenhadas dentro da estrutura social passam então a ser distinguidas segundo a definição legal de certos "comportamentos socialmente negativos", imposta a partir da visão e dos interesses das classes dominantes, revelando a natureza política do ato de criminalização e afastando com vigor as idéias da pretensa "neutralidade científica" para ressaltar ainda mais que: "A ideologia dominante em uma formação social é, via de regra, a ideologia das classes dominantes"11.

Reforçando as características e o papel do sistema penal em uma sociedade estratificada de classes, temos evidenciado o crime e o criminoso como entes políticos. Para ser criminoso não basta a prática de determinado ato criminalizado em lei, mas além do desrespeito a um preceito contido em norma penal é preciso pertencer as classes economicamente inferiores. É a presença cumulativa destes dois fatores (mais especificamente do segundo) que ativa a intervenção do sistema penal por representar grave ofensa ao princípio político de que deve existir uma passiva submissão à tirania dos grupos dominantes, pois "não é matar ou roubar o que se penaliza, mas a atitude de rebeldia contra as estruturas que tais atos estejam a revelar,12.

\section{CONSIDERAÇÕES FINAIS}

$\mathrm{Na}$ busca pelo efetivo prestígio dos Direitos Humanos é preciso derrubar certos mitos antigos, erigidos em torno da questão das drogas ilícitas - dentre outras questões penais como a redução da maioridade penal, a adoção da pena de morte e a aplicação massiva de penas privativas de liberdade cada vez maiores - e que apenas serviram (e servem) para justificar uma logística penalista bem como o controle social penal das "classes perigosas", dos inúteis, dos incômodos, dos desajustados e inadaptáveis - como se expôs linhas acima - daqueles que não

10 CAPELLER, Wanda Maria de Lemos. Criminalidade estrutural: aspectos ideológicos do controle social. In: Revista de Direito Penal e Criminologia n.․ 34. Rio de Janeiro: Forense, jul-dez/1982. p 69.

11 CAPELLER, Wanda Maria de Lemos. op. cit. p. 67.

12 THOMPSON, Augusto. Quem são os criminosos? Rio de Janeiro: Achiamé, 1983. p. 134. 
desempenham nenhum papel dentro do atual esquema capitalista de produção (propriedade privada dos meios de produção e venda de força de trabalho, pelo preço de salário ${ }^{13}$ ) e, atualmente, "de consumo". Afinal, repita-se, como impor a disciplina do trabalho a um contingente cada vez maior de pessoas desempregadas? A um exército crescente que revela a própria incoerência do sistema?

Os mitos do senso comum são fecundados a partir de imagens/valores/ estereótipos transmitidos pelos agentes oficiais, com incisiva determinação dos interesses políticos que os forjaram e que, mesmo se revestindo de uma certa técnica, não são absolutamente neutros, mas revelam a rançosa persistência daquele velho e mórbido olhar lombrosiano e darwinista concebido nos fins do séc. $X I X .^{14}$

Entretanto, deve prevalecer a solidariedade humana sobre a disciplina, pensar o contrário é aplicar o Direito Penal em descompasso com nossa realidade social, principalmente se estamos tratando do Sistema Penal cuja principal justificativa centra-se na pretensa "defesa social". Sempre que houver menção a palavra "sociedade", há de ser considerados indiscriminadamente todos os indivíduos que a integram, já que de outro modo restaria evidenciada apenas uma nítida tendência genocida, manifestando-se como um sintoma de uma estrutura social excludente e discriminatória.

Löic Wacquant, em recente estudo, destaca o fato de que nas sociedades ocidentais pós-guerra está acontecendo uma substituição progressiva de um (semi) Estado-providência por um Estado penal e policial em que a criminalização da marginalidade e a contenção punitiva das categorias deserdadas faz as vezes de política social. Além disso, a progressiva retratação do Estado Social conjugada ao crescimento constante do Estado Penal tem revelado o surgimento de um "Estado centauro gerado por uma cabeça liberal montada sobre um corpo autoritarista". ${ }^{15}$

\footnotetext{
13 SANTOS, Juarez Cirino dos. Violência Institucional. In: Revista de direito penal, n.o 28, jul./dez 1979, Rio de Janeiro: Instituto de Ciências Penais do Rio de Janeiro: Forense. p.

14 BATISTA, Vera Malaguti. Difíceis ganhos fáceis: drogas e juventude pobre no Rio de Janeiro. Rio de Janeiro: Instituto Carioca de Criminologia: Freitas Bastos, 1998. p. 106.

15 WACQUANT, Löic. Punir os pobres: a nova gestão da miséria nos Estados Unidos. Rio de Janeiro: Instituto Carioca de Criminologia: Freitas Bastos, 2001. pp. 20-1.
} 
Consoante estudo apresentado no $7^{\circ}$ Simpósio Internacional de Vitimologia (RJ/agosto 1991), todos precisam ser urgentemente esclarecidos dos males decorrentes do uso de drogas. Mas estas informações devem ser levadas com respeito à dignidade e a individualidade humana, o respeito ao outro. A comunidade deve intensificar os seus esforços para conhecer e delimitar o uso de drogas (tanto lícitas como ilícitas) e também para prestar solidariedade àqueles que estão expostos e sofrem diretamente como integrantes de um grupo de risco, para que eles saibam que não estão sozinhos. ${ }^{16}$

O Estado pode e deve sim otimizar o processo de recuperação e tratamento, mas não fazendo uso do sistema penal que comprovadamente não tem a capacidade de resolver a situação de maneira adequada.

Não pode ser convalidada a racionalização da seletividade decisória sob a idéia de "igualdade e segurança jurídica", uma vez que o déficit de tutela real dos direitos humanos é compensado pela ilusão criada no senso comum de uma segurança jurídica e de uma cega confiança no Direito Penal e nas instituições de controle. ${ }^{17}$

Consoante perspicaz formulação de Eugenio Raúl Zaffaroni, para a construção de um Direito Penal Igualitário existem certos princípios para a limitação da violência por exclusão de pressupostos de disfuncionalidade grosseira para os Direitos Humanos que devem ser atendidos, como exemplo o Princípio da Limitação Máxima da Resposta Contingente, que é um "indicador retor" para que todas as agências judiciais assegurem a aplicação de um ideário repressivo oriundo de um amplo debate público e participativo, para "velar pela supremacia constitucional que exige das agências legislativas uma ética republicana".18

Todavia, repita-se, não há que se olvidar o equacionamento destas e de outras situações existentes dentro da atual Política Criminal brasileira no que tange ao problema das drogas ilícitas.

16 CAMPOS, Benedito Roque da Silveira. Prevenção ao uso indevido de drogas - aspectos vitimológicos. In KOSOVSKI, Ester. Vitimologia: enfoque interdisciplinar. Rio de Janeiro: Reproarte, 1993. p.45.

17 ANDRADE, Vera Regina Pereira de. A ilusão da segurança jurídica: do controle da violência à violência do controle penal. Porto Alegre: Livraria do Advogado, 1997. p. 313.

18 ZAFFARONI, Eugenio Raúl. Em busca das penas perdidas: a perda de legitimidade do sistema penal. tradução Vania Romano Pedrosa, Amir Lopes da Conceição. Rio de Janeiro: Revan, 1991. p. 240. 
Se estas questões ainda não foram debatidas de maneira satisfatória, não há com que se preocupar, porquanto "a constituição do direito é, mesmo, uma faceta do processo histórico-social e sócio-político"19, ou seja, deve estar em constante mutação para acompanhar a evolução da sociedade, e só assim estar apto a atender as necessidades desta. Neste sentido, deve existir o compromisso da comunidade jurídica em revelar e buscar uma solução para as possíveis incongruências existentes entre os diversos textos normativos, sempre em benefício da norma de hierarquia superior, caso contrário compromete-se à estrutura do próprio sistema jurídico e, em ultima análise, a defesa da sociedade e a necessária efetivação dos Direitos Humanos.

\section{BIBLIOGRAFIA}

ANDRADE, Vera Regina Pereira de. A ilusão da segurança jurídica: do controle da violência à violência do controle penal. Porto Alegre: Livraria do Advogado, 1997.

BARATTA, Alessandro. Criminologia crítica e crítica do direito penal: introducãa à sociologia do direito penal. Tradução de Juarez Cirino dos Santos. $2^{\mathrm{a}}$ ed. Rio de Janeiro: Freitas Bastos: Instituto Carioca de Criminologia, 1999.

BATISTA, Nilo. Política criminal com derramamento de sangue. In: Revista Brasileira de Ciências Criminais, n.ำ 20, São Paulo: Ed. Revista dos Tribunais, 1997.

Punidos e mal pagos: violência, justiça, segurança pública e direitos humanos no Brasil de hoje. Rio de Janeiro: Revan, 1990.

BATISTA, Vera Malaguti. Difíceis ganhos fáceis: drogas e juventude pobre no Rio de Janeiro. Rio de Janeiro: Instituto Carioca de Criminologia: Freitas Bastos, 1998.

A construção do transgressor. Texto distribuído aos Alunos do Mestrado em Criminologia e Direito Penal da Universidade Cândido Mendes (UCAM-RJ). Rio de Janeiro, 2000.

CAMPOS, Benedito Roque da Silveira. Prevenção ao uso indevido de drogas - aspectos vitimológicos. In KOSOVSKI, Ester. Vitimologia: enfoque interdisciplinar. Rio de Janeiro: Reproarte, 1993.

CAPELLER, Wanda Maria de Lemos. Criminalidade estrutural: aspectos ideológicos do controle social. In: Revista de Direito Penal e Criminologia n.. 34. Rio de Janeiro: Forense, jul-dez/1982.

19 LYRA, Roberto. Carta aberta a um jovem criminólogo: teoria, práxis e táticas atuais. In: Revista de direito penal, n. ㅇ 28, jul./dez 1979, Rio de Janeiro: Instituto de Ciências Penais do Rio de Janeiro: Forense. p. 14. 
CONSTITUIÇÃO DA REPÚBLICA FEDERATIVA DO BRASIL: promulgada em 5 de outubro de 1988/ obra coletiva de autoria da editora Saraiva com a colaboração de Antonio Luiz Toledo Pinto, Márcia Cristina Vaz dos Santos Windt e Luiz Eduardo Alves Siqueira. 27ํㅡㄹ. ed. São Paulo: Saraiva, 2001.

DIAS, Jorge de Figueiredo, ANDRADE, Manuel da Costa. Criminologia: o homem delinqüente e a sociedade criminógena. Coimbra: Coimbra Editora Limitada, 1992.

LYRA, Roberto. Carta aberta a um jovem criminólogo: teoria, práxis e táticas atuais. In: Revista de direito penal, n.․ 28, jul./dez. 1979, Rio de Janeiro: Instituto de Ciências Penais do Rio de Janeiro: Forense.

MENNA BARRETO, João de Deus Lacerda. Estudo geral da nova lei de tóxicos. $3^{\text {a }}$ ed. rev. e aumentada. Rio de Janeiro: Freitas Bastos, 1982.

DEL OLMO, Rosa. A face oculta da Droga. Tradução de T. Ottoni. Rio de Janeiro: Revan, 1990.

SANTOS, José Wilson Seixas. Lei antitóxicos comentada. $2^{\underline{a}}$ ed. rev. atual. Leme: Livraria de Direito, 1994. P. 56.

SANTOS, Juarez Cirino dos. Violência Institucional. In: Revista de direito penal, n.ำ 28, jul./dez 1979, Rio de Janeiro: Instituto de Ciências Penais do Rio de Janeiro: Forense.

THOMPSON, Augusto. Quem são os criminosos? Rio de Janeiro: Achiamé, 1983.

WACQUANT, Löic. Punir os pobres: a nova gestão da miséria nos Estados Unidos. Rio de Janeiro: Instituto Carioca de Criminologia: Freitas Bastos, 2001.

ZAFFARONI, Eugenio Raúl. Em busca das penas perdidas: a perda de legitimidade do sistema penal. Tradução Vania Romano Pedrosa, Amir Lopes da Conceição. Rio de Janeiro: Revan, 1991. 